\title{
Mycotic Infections in Diabetic Patients in Casablanca
}

\author{
Annelie Kérékou ${ }^{1,2}$, Siham El Aziz ${ }^{2}$, Alihonou Dédjan ${ }^{1,2}$, Asma Chadli², Ahmed Farouqi² \\ ${ }^{1}$ Endocrinology, Metabolism and Nutrition Department CNHU-HKM, Cotonou, Bénin \\ ${ }^{2}$ Endocrinology, Diabetology and Metabolic Diseases Department, Ibn Rochd University Hospital Center of Casablanca, \\ Casablanca, Morocco \\ Email: kerekouannelie@yahoo.fr
}

How to cite this paper: Kérékou, A., El Aziz, S., Dédjan, A., Chadli, A. and Farouqi, A. (2019) Mycotic Infections in Diabetic Patients in Casablanca. Journal of Diabetes Mellitus, 9, 146-151.

https://doi.org/10.4236/jdm.2019.93014

Received: March 29, 2019

Accepted: August 19, 2019

Published: August 22, 2019

Copyright (c) 2019 by author(s) and Scientific Research Publishing Inc. This work is licensed under the Creative Commons Attribution International License (CC BY 4.0).

http://creativecommons.org/licenses/by/4.0/

cc) (i) Open Access

\begin{abstract}
Introduction: The diabetes constitutes the factor risk of mycotic infections. The pathogenic agents depend on the climate, geography and the migration. The objective of this study is to evaluate the prevalence of the mycotic infections within the hospitalized diabetic patients, to describe their localization and identify the responsible germs. Patients and methods: It is about a descriptive and retrospective study conducted from November 2015 to March 2016 in endocrinology office at CHU Ibn Roch of Casablanca. It was included all diabetic patients hospitalized with whom mycotic infection has been suspected. Results: In total 350 diabetic patients have been hospitalized during the period of research. A mycotic infection has been suspected in 138 patients corresponding to the prevalence of 39.4 percent. The means localizations of mycotic infections were feet (intertrigos: $38.4 \%$ ), onychomycosis (29\%), vulvovaginal (21.7\%) and mouth (oral candidiasis: 13.3\%). The most frequent pathogenic agents were dermatophytes (Trichophyton rubrum: 61\%, Trichophyton mentagrophytes. 6.3\%) and Candida albicans (23.1\%). The direct test and the culture were negative in $7.3 \%$. Conclusion: One-third of the diabetic patients showed a mycotic infection. The feet, constitute the predilection localization of mycotic infections in the diabetic. The dermatophytes and Candida albicans constitute the most frequent pathogenic agents found in our study.
\end{abstract}

\section{Keywords}

Mycotic, Infection, Diabetes, Dermatophytes

\section{Introduction}

The diabetes constitutes a contributing factor to mycotic infections. This is due 
to altered powers of phagocytosis and chemotaxis of white blood cells. The infections frequently described are the orodigestive candidiasis, the intertrigos, the onychomycosis, the perleches, the vulvovaginitis, the balanites and the paronychia [1]. Onychomycosis prevalence reaching 26 to 35 percent in the diabetic patients, higher than in non diabetics. An intertrigo is estimated to 32 percent in the diabetic population against 7 percent in non-diabetics [2]. The relative risk of onychomycosis is estimated between 1.5 and 2.8 according to the studies in the diabetics on relation with the general population and the risk of intertrigo at 2.3 [3]. The pathogenic agents depend on the climate, geography and the migration [4]. The objective of this study is to evaluate the prevalence of the mycotic infections within the hospitalized diabetic patients, to describe their localization and identify the responsible germs.

\section{Patients and Methods}

It is about a descriptive and retrospective study conducted from November 2015 to March 2016 in endocrinology office at CHU Ibn Roch of Casablanca.

It was included all diabetic patient hospitalized with whom mycotic infection has been suspected. The samples are taken in parasitology laboratory. The variable studied concerned the clinic signs, their localization, the paraclinics data. The data collection has been done with questionnaire and statistical analysis with software SPSS 20.0

\section{Results}

\section{Socio-demographic characteristic}

In total 350 diabetic patients have been hospitalized during the period of research (6 months). A mycotic infection has been suspected in 138 patients corresponding to the prevalence of 39.4 percent. The average age was $50 \pm 8$ years and a sex-ratio $(\mathrm{H} / \mathrm{F})$ of 0.64 . Antecedent of mycotic infection has been found in 50 percent of patients. The mean duration of diabetes was $13 \pm 5$ years (Table 1 ).

\section{Clinical aspects}

In 138 patients the intertrigos were found in 53 patients (38.4 percent), the onychomycosis in 40 patients (29 percent), an association of intertrigos and onychomycosis in 23 patients (16.6), the oral candidiasis in 17 patients (13.3 percent), the vulvovaginitis in 12 female patients (21.7 percent), the mycosis of large folds (under breast and or inguinal) in 11 patients (7.99 percents), an association of vulvovaginitis and mycosis of the large folds in 10 female patients(7.2 percent), the urinary tract infection in three female patients (2.17 percents), digestive candidiasis revealed in the gastroscopy in two patients (1.4 percents) (Table 2).

The mycosis is not linked to the sex as it shows the value of chi carre $=0.2562$ ( $p=0.6128$ ), also the mycotic infection is not associated to a particular type of diabete $(\mathrm{p}=0.2568)$.

Figure 1 shows a macerated intertrigo responsible of an erysipelas and Figure 2 shows an oral candidiasis. 
Table 1. Socio-demographic characteristic of diabetics patients suspected with mycotic infection.

\begin{tabular}{ccccc}
\hline & Diabete type 1 & Diabete type 2 & Total & P value \\
\hline Total & 20 & 118 & 138 & \\
Age (years) & $28 \pm 6$ & $54 \pm 9$ & $50 \pm 8$ & \\
Sex-ratio H/F & $11 / 9$ & $43 / 75$ & 0.64 & 0.6128 \\
HbAlc & $9.2 \pm 1.5 \%$ & $10.8 \pm 2.1 \%$ & $10.5 \pm 2$ & 0.2568 \\
Duration of diabetes (years) & 7 & 14 & $13 \pm 5$ & \\
Antecedent of mycotic infection & 5 & 65 & $50 \%$ & \\
\hline
\end{tabular}

Table 2. Localization of mycosis infection.

\begin{tabular}{ccc}
\hline Localization of mycosis infection & Total & Frequence \\
\hline Intertrigo & 53 & $38.4 \%$ \\
Onychomycosis & 40 & $29 \%$ \\
Oral candidiasis & 17 & $13.3 \%$ \\
Vulvo-vaginitis & 12 & $21.7 \%$ \\
mycosis of large folds & 11 & $8.7 \%$ \\
urinary tract infection & 3 & $2.17 \%$ \\
digestive candidiasis & 2 & $1.4 \%$ \\
Association Vulvo-vaginitis and mycosis of large folds & 10 & $7.2 \%$ \\
Association Onychomycosis and intertrigo & 23 & $16.6 \%$ \\
\hline
\end{tabular}

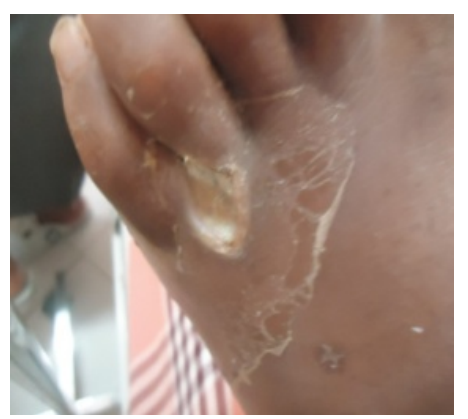

Figure 1. Intertrigo macerated responsible of an erysipelas.

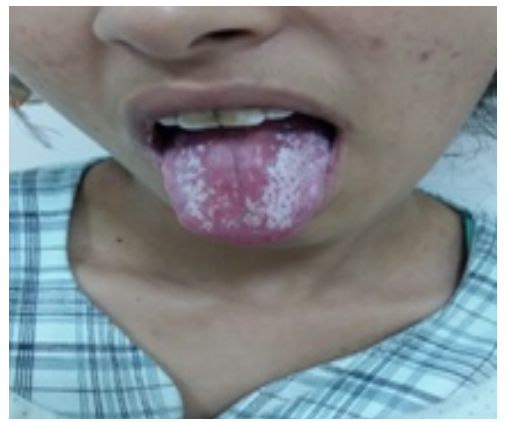

Figure 2. Oral candidiasis. 


\section{Paraclinic aspects}

They were all in chronic imbalance glycemy with an average hemoglobin glycated of $10.5 \pm 2$ percent.

By the lack of means, it is only in 95 patients that we have been able to realize a mycological test. The Trichophyton rubrum was identified in 58 patients (61 percents), the Trichophyton mentagrophytes in 6 patients (6.3 percents), the Candida albicans in 23 patients (23.1 percents) and the Candida parapsilosis in two patients (2.1 percents).

The direct test and the culture were negative in seven patients ( 7.3 percent). It therefore appears that the confirmation rate is 92.6 percent (Table 3 ).

\section{Discussion}

The mean age of our study population is $50 \pm 8$ years and this is due to the predominance of the type 2 diabetic patients. This mean age is inferior to what found by El Fékih N and al [5] and Gupta A.K et al. [3] which were respectively $55 \pm 8$ years and $56.1 \pm 7$ years.

J. Fergermann and al have estimated at least the third of diabetic patients who would present an onycomychosis which corroborate our results in which $29 \%$ of the patients show an onychomycosis [4].

In our study the mycosis is not linked to the sex whereas Eckhard $\mathrm{M}$ and al have found that foot mycosis infections are more frequent in males [6].

The mycotic infection is not associated to a particular diabete in our research.

The mean duration of diabetes was $13 \pm 5$ years in our research which is similar to $15.3 \pm 1.2$ years found by Gupta A.K and al [3].

The most frequent localizations of mycosis are the inter toe space and the nail which correspond with the results of El Fékih and al [5]. The intertrigo constitutes the veritable gaterway for the bacterial infections potentially serious such as the erysipelas, the cellulitis and the fasciitis.

Our research reveals the rate of suspicions of mycosis infection at 39.4percent, inferior to the rates of 46 percent and 53.7 percent found respectively by Gupta and al and El Fékih and al.

Table 3. Results of mycological test.

\begin{tabular}{ccccccc}
\hline & Total & T rubrun & T mentagrophytes & C albicans & C parasilosis & Sterile \\
\hline Intertrigo & 39 & 34 & 3 & - & - & 2 \\
Onychomycosis & 27 & 24 & 1 & & 1 & 1 \\
Oral candidiasis & 12 & & & 9 & 1 & 2 \\
Vulvovaginitis & 7 & & 2 & 2 & & 1 \\
Mycosis of large folds & 5 & & & 3 & & 1 \\
Urinary tract infection & 3 & & & 2 & & \\
Digestive candidiasis & 2 & & & & & \\
TOTAL & & $58(61 \%)$ & $6(6.3 \%)$ & $22(23.1 \%)$ & $2(2.1 \%)$ & $7(7.3 \%)$
\end{tabular}

Abbreviation: $\mathrm{T}=$ trichophyton $\mathrm{C}=$ candida . 
The rates of confirmation of mycotic infections in our study are 92.6 percent (88/95) comparable to that of El Fékih and al who have confirmed the mycotic infection in 81 patients over the 86 patients suspected of mycotic infection. Our rate is superior to that of Gupta A. K and al who have confirmed the mycosic infection in 144 patients over 253 patients suspected.

In our research the dermatophytes are the pathogenic agents most frequents in mycotic infection of feet. This is similar to results of a lot of authors [7] [8]. The Trichophyton rubrum is the most frequent dermatophyte [6] [9] [10].

Candida albicans appears to be more common in the mucosa in our study, which is comparable to the results of Jhugroo $\mathrm{C}$ et al., who found that mycotic infections in the mouth of the diabetic were due mainly to Candida albicans [11].

The glycemic imbalance noticed in our patients could explain itself by the fact they have been hospitalized in the framwork of glycemic imbalance or of a diabete decompensation. This glycemic imbalance is seen in most study [5] [11].

\section{Conclusion}

One third of the diabetic patients showed a mycotic infection. All the diabetics' patients presenting a mycotic infection were in chronic glycemic imbalance. The feet constitute the predilection localization of mycotic infections in the diabetic. The dermatophytes constitute the most frequent pathogenic agents found.

\section{Conflicts of Interest}

The authors declare no conflicts of interest regarding the publication of this paper.

\section{References}

[1] Senet, P. and Chosidow, O. (2002) Manifestations cutanéomuqueuses du diabète. Encycl Méd Chir (Editions Scientifiques et Médicales Elsevier SAS, Paris, tous droits réservés), Endocrinologie-Nutrition, $5 \mathrm{p}$.

[2] Yosipovitch, G., Hodak, E., Vardi, P., Shraga, I., Karp, M., Sprecher, E., et al. (1998) The Prevalence of Cutaneous Manifestations in DM Patients and Their Association with Diabetes Risk Factors and Microvascular Complications. Diabetes Care, 21, 506-509. https://doi.org/10.2337/diacare.21.4.506

[3] Gupta, A.K. and Humke, S. (2000) The Prevalence and Management of Onychomycosis in Diabetic Patients. European Journal of Dermatology, 10, 379-384.

[4] Faergemann, J. and Baran, R. (2003) Epidemiology, Clinical Presentation and Diagnosis of Onychomycosis. British Journal of Dermatology, 149, 1-4. https://doi.org/10.1046/j.1365-2133.149.s65.4.x

[5] El Fékih, N., Fazaa, B., Zouari, B., et al. (2009) Les mycoses du pied chez le diabétique: Études prospectives de 150 patients. Journal de Mycologie Médicale, 19, 29-33. https://doi.org/10.1016/j.mycmed.2008.12.005

[6] Eckhard, M., Lengler, A., Liersch, J., Bretzel, R.G. and Mayser, P. (2011) Fungal Foot Infections in Patients with Diabetes Mellitus-Results of Two Independent Investigations. Mycoses, 50, 49-54. https://doi.org/10.1111/j.1439-0507.2007.01425.x 
[7] Cathcart, S., Cantrell, W. and Elewski, B.E. (2009) Onychomycosis and Diabetes. Journal of the European Academy of Dermatology and Venerology, 23, 1119-1122. https://doi.org/10.1111/j.1468-3083.2009.03225.x

[8] Gupta, A.K., Jain, H.C., Lynde, C.W., et al. (1997) Prevalence and Epidemiology of Unsuspected Onychomycosis in Patients Visiting Dermatologists' Offices in Ontario, Canada: A Multicenter Survey 2001 Patients. International Journal of Dermatology, 36, 783-787. https://doi.org/10.1046/j.1365-4362.1997.00349.x

[9] Poradzka, A., Jasik, M., Karnafal, W. and Fiedor, P. (2013) Clinical Aspects of Fungal Infections in Diabetes. Acta Poloniae Pharmaceutica-Drug Research, 70, 587-596.

[10] Gulcan, A., Gulcan, E., Oksuz, S., Sahin, I. and Kaya, D. (2011) Prevalence of Toenail Onychomycosis in Patients with Type 2 Diabetes Mellitus and Evaluation of Risk Factors. Journal of the American Podiatric Medical Association, 101, 49-54.

[11] Jhugroo, C., Divakar, D.D., Jhugroo, P., et al. (2019) Characterization of Oral Mucosa Lesions and Prevalence of Yeasts in Diabetic Patients: A Comparative Study. Microbial Pathogenesis, 126, 363-367.

https://doi.org/10.1016/j.micpath.2018.11.028 